\title{
Effect of the Energy Source on Changes in Energy Expenditure, Respiratory Quotient, and Nitrogen Balance during Total Parenteral Nutrition in Children
}

\author{
OSAMU NOSE, JAMES R. TIPTON, MARVIN E. AMENT, AND HYAKUJI YABUUCHI \\ Department of Pediatrics, Osaka University School of Medicine, Osaka, Japan and Department of Pediatrics, \\ University of California, Los Angeles, California 90024
}

\begin{abstract}
The effects of three isocaloric intravenous nutritional regimens were studied in seven infants and children, ages 2 months to $9 \mathrm{yr}$, with congenital gastrointestinal anomalies (four patients) or with prior history of malignant disease admitted in remission for bone marrow transplantation (three patients). Energy metabolism, as measured by the basal metabolic rate (BMR), and substrate utilization, as measured by the respiratory quotient (RQ), were studied to determine the effect of different levels of carbohydrate and fat on nitrogen retention in each patient. Solution A provided $8 \%$ of energy as amino acids, $87 \%$ as carbohydrate, and $5 \%$ as fat. Solution B provided $8 \%$ of energy as amino acids, $60 \%$ as carbohydrate, and $32 \%$ as fat. Solution $C$ provided $8 \%$ of energy as amino acids, $\mathbf{3 4 \%}$ as carbohydrate, and $\mathbf{5 8 \%}$ as fat. Administration of solution A (high carbohydrate, low fat) was associated with moderately increased mean $( \pm S D) B M R$ and RQ and with low nitrogen retention $(19.1 \pm 12.7 \%, 1.06 \pm$ 0.14 , and $98 \pm 28 \mathrm{mg} \mathrm{N} / \mathrm{kg} / \mathrm{day}$ ). Both the BMR and the RQ decreased when less carbohydrate and more lipid was given: BMR $4.3 \pm 11.6 \%(p<0.005)$, RQ $0.92 \pm 0.09(p$ $<0.001)$ for solution B; BMR $3.94 \pm 10.6 \%(p<0.005)$, RQ $0.86 \pm 0.09(p<0.001)$ for solution C. Among the solutions tested, optimal nitrogen retention $[163 \pm 60 \mathrm{mg}$ $\mathrm{N} / \mathrm{kg} / \mathrm{day}(p<0.01)]$ was noted with solution B. Our data support the conclusion that a physiologic balance of fat and carbohydrate results in optimal nitrogen retention. (Pediatr Res 21: 538-541, 1987)
\end{abstract}

\section{Abbreviations}

TPN, total parenteral nutrition

CBC, complete blood count

$\mathrm{VO}_{2}$, oxygen consumption

$\mathrm{VCO}_{2}$, carbon dioxide production

$R Q$, respiratory quotient

$\mathrm{FeCO}_{2}$, measured $\mathrm{CO}_{2}$ concentration of expired air

$\mathrm{FeO}_{2}$, measured $\mathrm{O}_{2}$ concentration of expired air

$\mathrm{FiO}_{2}, \mathrm{O}_{2}$ concentration in room air

$\mathrm{VE}$, flow rate

BMR, basal metabolic rate

ANOVA, two-way analysis of variance

Techniques for providing complete nutritional support parenterally are of great importance in the management of infants

Received October 2, 1986; accepted December 24, 1986

Reprint requests and correspondence: Marvin E. Ament, M.D., Room MDCC 22-340, Department of Pediatrics, UCLA Medical Center, Los Angeles, CA 90024. and children with short bowel syndrome, seriously damaged intestinal mucosa, or failure to develop intestinal villi. Several reports (1-4) have assessed the relationship between nitrogen balance and the energy sources. In adult patients with severe catabolic states, most of the patients were recovering from severe injuries or had septic complications of accidental or surgical trauma. However, no similar studies are available in infants or children. The present study examined, in children, the metabolic effects, including nitrogen retention, of three different isocaloric TPN solutions which varied only in the proportion of calories derived from fat and carbohydrate.

\section{PATIENTS AND METHODS}

Patients. Seven patients were studied over a period of 15 days (Table 1). Four were infants, ages 2 to 5 months, with congenital gastrointestinal anomalies. They had been stable on TPN at least 10 days after the acute postoperative period. Three others were children, 3 to 9 yr of age, with arrested malignant disease (one had acute lymphoblastic leukemia and two had neuroblastoma). All had been on chemotherapy and were presently hospitalized for bone marrow transplantation. Subsequently, they could not take adequate food orally because of gingivostomatitis, nausea, vomiting, or loss of appetite. In all cases, more than $90 \%$ of their nutrients were supplied parenterally. Human Subject Protection Committee approval and their parents' informed consent were obtained for this study.

Study design. Three consecutive study periods, each lasting 35 days, were compared. The total energy, electrolytes, trace minerals, and vitamins were identical for all the solutions. However, the composition of the energy source varied, as shown in Table 2. Each regimen was given through a random cross-over design. A crystalline amino acid solution (10\% Travesol) was used to provide the nitrogen source. Glucose and fat $(20 \%$ Intralipid) were used as the nonprotein energy sources. Infants below $10 \mathrm{~kg}$ of body weight received a mean $( \pm \mathrm{SD}) 123.3 \pm 6.3$ $\mathrm{ml} / \mathrm{kg} /$ day and $95 \pm 6 \mathrm{kcal} / \mathrm{kg} /$ day. Children more than $10 \mathrm{~kg}$ received $100 \mathrm{kcal} / \mathrm{kg} /$ day for the first $10 \mathrm{~kg}, 50 \mathrm{kcal} / \mathrm{kg} /$ day for the next $10 \mathrm{~kg}$, and $20 \mathrm{kcal} / \mathrm{kg} / \mathrm{day}$ for each $\mathrm{kg}$ beyond the 20 th $\mathrm{kg}$. Their average caloric intake was $91 \pm 5 \mathrm{kcal} / \mathrm{kg} /$ day. Each $125 \mathrm{ml}$ of TPN solution delivered $90 \mathrm{cal}$ to all patients on all solutions.

Although there were some minor variations in the volumes of TPN solution delivered to different individuals, the solution volumes and calories delivered to each individual were similar during the three study phases. The nutrients were given concurrently and continuously by infusion pump via a central vein. CBC and platelet count, and plasma SGOT, SGPT, bilirubin (total and direct), creatinine, and plasma and urinary glucose were routinely checked every other day. Serum insulin, free fatty 
Table 1. Characteristics of patients studied with three different isocaloric parenteral nutrition formulas in study of BMR and $R Q$

\begin{tabular}{|c|c|c|c|c|}
\hline Patient & $\begin{array}{c}\text { ID } \\
\text { mark }\end{array}$ & Sex & Age & Diagnosis \\
\hline C.J. & & $\mathbf{M}$ & $2 \mathrm{yr} 11 \mathrm{mo}$ & Neuroblastoma for BMT* \\
\hline P.A. & & $\mathbf{M}$ & $5 \mathrm{mo}$ & Short bowel \\
\hline H.T. & & M & $3 \mathrm{yr} 11 \mathrm{mo}$ & Neuroblastoma for BMT \\
\hline D.K. & & M & 9 yr 4 mo & Leukemia for BMT \\
\hline R.M. & & $\mathbf{M}$ & $2 \mathrm{mo}$ & Gastroschisis \\
\hline Z.C. & & $\mathbf{M}$ & $2 \mathrm{mo}$ & Short bowel \\
\hline M.R. & & $\mathrm{F}$ & $5 \mathrm{mo}$ & Short bowel \\
\hline
\end{tabular}

* Bone marrow transplantation.

Table 2. Caloric distribution of three TPN formulas*

\begin{tabular}{lcrr}
\hline & Solution & Solution & \multicolumn{1}{c}{ Solution } \\
& A $(\%)$ & \multicolumn{1}{c}{ B $(\%)$} & \multicolumn{1}{c}{ C $(\%)$} \\
\hline Glucose & $86.6 \pm 0.5$ & $60.0 \pm 2.0$ & $35.5 \pm 2.4$ \\
Lipid & $5.4 \pm 0.45$ & $32.07 \pm 2.5$ & $56.6 \pm 2.2$ \\
Amino Acid & $8.0 \pm 0.0$ & $7.93 \pm 0.3$ & $8.0 \pm 0.2$ \\
\hline
\end{tabular}

* Values recorded as mean and SEM percentage of calories from glucose, lipid, or amino acid.

acids, $\beta$-hydroxybutyrate, triglycerides, and transferrin levels were measured quantitatively. Quantitative urine collections for total nitrogen and amino acid nitrogen were performed on the last day of administration of each solution, concurrent with measurement of the resting energy expenditure.

Laboratory studies. Three to $5 \mathrm{ml}$ of blood were drawn for free fatty acids, insulin, triglyceride, $\beta$-hydroxybutyrate, and transferrin. Blood samples were transferred into heparinized tubes, which were kept at $+4^{\circ} \mathrm{C}$ until centrifugation. Plasma was separated within $30 \mathrm{~min}$ and stored at $-20^{\circ} \mathrm{C}$ for subsequent analysis. Plasma free fatty acids, insulin, and triglycerides, as well as electrolytes, liver function studies, creatinine, and glucose were determined by conventional methods in our hospital laboratory. Transferrin concentration was determined by laser nephelometry. Urinary total nitrogen was determined by the Kjeldahl method, and urinary amino acid nitrogen was measured by an enzymatic method. Nitrogen balance was derived from the daily volume of infusate minus the daily output of urinary nitrogen. Great care was taken to avoid urine loss, and urine collections were completed equally in all three periods, except for patient C.J.

Determination of energy expenditure and substrate utilization. $\mathrm{VO}_{2}$ and $\mathrm{VCO}_{2}$ were measured by open circuit, indirect calorimetry utilizing a system developed in this laboratory (Fig. 1). A stream of room air $(0.5-1.0 \mathrm{l} / \mathrm{kg} / \mathrm{min})$ was drawn at a constant flow rate (Minato, Respiromonitor RM-100 flow meter and Ueshima Seisakusho Co. flow controller) through a Lucite rigid hood placed loosely over the head of the resting, supine patient. Each patient could breathe freely. The difference between the oxygen concentration in room air and that in the mixture of room air and expired gases was measured by a solid electrolyte oxygen detector (Engineering Research Laboratories, Toray Industries, Inc.). The difference between the $\mathrm{CO}_{2}$ concentration in expired air as compared to room air was determined by infrared analyzer. The system allows continuous measurement of oxygen consumption and carbon dioxide production which are displayed on a chart recorder. The following formulae were used.

$$
\begin{gathered}
\mathrm{VO}_{2}=\left|\frac{\left(1-\mathrm{FeCO}_{2}-\mathrm{FeO}_{2}\right)}{\left(1-\mathrm{FiO}_{2}\right)} \times \mathrm{FiO}_{2}-\mathrm{FeO}_{2}\right| \times \mathrm{VE} \\
\mathrm{VCO}_{2}=\mathrm{FeCO}_{2} \times \mathrm{VE} \\
\mathrm{RQ}=\frac{\mathrm{VCO}_{2}}{\mathrm{VO}_{2}}
\end{gathered}
$$

Patients were left undisturbed until a steady state was achieved. The mean value of oxygen consumption over $30 \mathrm{~min}$ was then recorded. The open circuit, indirect calorimeter was calibrated daily by standard $\mathrm{O}_{2}$ and $\mathrm{CO}_{2}$ for accuracy and was checked by burning pure alcohol under standard conditions. Recovery of mean $( \pm$ SD) $97.8 \pm 3.3 \%$ for oxygen and $96.3 \pm 3.2 \%$ for carbon dioxide, and an RQ variance of $0.67 \pm 0.01 \%$ were obtained $(n$ $=10$ ). Energy expenditure and the amounts of different fuels used were calculated by the formulae of Consolazio et al. (5) (a modification of Lusk's tables). The energy expenditure was normalized and expressed as BMR on the basis of predicted energy expenditure.

Statistical analysis. Since the three experimental conditions $\mathrm{A}, \mathrm{B}$, and $\mathrm{C}$ were set in gradual fashion and interrelated, multiple comparisons among them for each measurement was made by use of ANOVA. When there were one or two missing measurements, these were supplemented by estimated values calculated from the mean of the whole data and means of the corresponding row and column. The degree of freedom was adjusted accordingly.

\section{RESULTS}

Hematologic and biochemical monitoring. Throughout the study period, hematologic data (CBC and platelet count) and biochemical parameters (electrolytes, creatinine, total and direct bilirubin, SGOT, SGPT, and plasma and urinary glucose) were within normal limits for all patients, except for slight increases in SGOT and SGPT in two cases. In addition, plasma free fatty acid and triglyceride levels remained within normal limits throughout the study period, and no statistically significant differences were noted among the three solutions. While plasma insulin levels were maintained in the high normal range $(30 \pm$ $23 \mu \mathrm{U} / \mathrm{ml}$ ) for patients receiving solution $\mathrm{A}$, and showed a slight tendency to decrease as the percentage of glucose calories decreased, we could not demonstrate a statistically significant difference among the three solutions. Although serum transferrin tended to be higher $(172 \mathrm{mg} / \mathrm{dl})$ in patients on solution $B$, as compared to 156 and $158 \mathrm{mg} / \mathrm{dl}$ for solutions $\mathrm{A}$ and $\mathrm{C}$, respectively, differences among the three solutions tested were not statistically significant.

$B M R$ and $R Q$. Changes in the BMR and in the RQ are shown in Figures 2 and 3 . The mean $( \pm \mathrm{SD}) \mathrm{BMR}$ values during infusion of solutions $\mathrm{A}, \mathrm{B}$, and $\mathrm{C}$ were $19.1+12.7,4.3+11.6$, and 3.9 $+10.6 \%$, respectively. The mean BMR appeared to decrease significantly as the proportion of calories derived from lipid increased (and the proportion of calories derived from carbohydrate decreased). This trend was statistically significant $(p<$ $0.005)$. The mean $( \pm \mathrm{SD}) \mathrm{RQ}$ values were $1.06+0.14,0.92+$ 0.09 , and $0.86+0.09$ for patients on solutions $\mathrm{A}, \mathrm{B}$, and $\mathrm{C}$, respectively. The mean $R Q$ also decreased significantly with the increase in propostion of fat calories of the solutions $(p<0.001)$.

Substrate utilization. Table 3 depicts the relative participation of glucose, fat, and protein oxidation in energy expenditure during each phase of the study. The distribution pattern of energy metabolism in terms of fat and carbohydrate utilization changed significantly when the composition of the energy sources was modified ( $p<0.05$ and $<0.01$, respectively), demonstrating that energy was derived from fat utilization when the percentage of lipid administered increased. Interestingly, the protein degradation rate was not strongly influenced by changes in the proportion of calories derived from fat or carbohydrate (Table 3 ).

Nitrogen balance. Administration of solution A (high carbohydrate, low fat) or solution $\mathrm{C}$ (low carbohydrate, high fat) resulted in comparatively less nitrogen retention $(98 \pm 28$ and $123 \pm 64 \mathrm{mg} / \mathrm{kg} /$ day, respectively), than administration of solution $\mathrm{B}(163 \pm 60 \mathrm{mg} / \mathrm{kg} /$ day, $p<0.05)$. Nitrogen retention was greatest or most efficient with solution B (Table 3 ).

\section{DISCUSSION}

Our study shows that patients receiving a glucose-dominant TPN solution as the energy source, containing only enough fat 

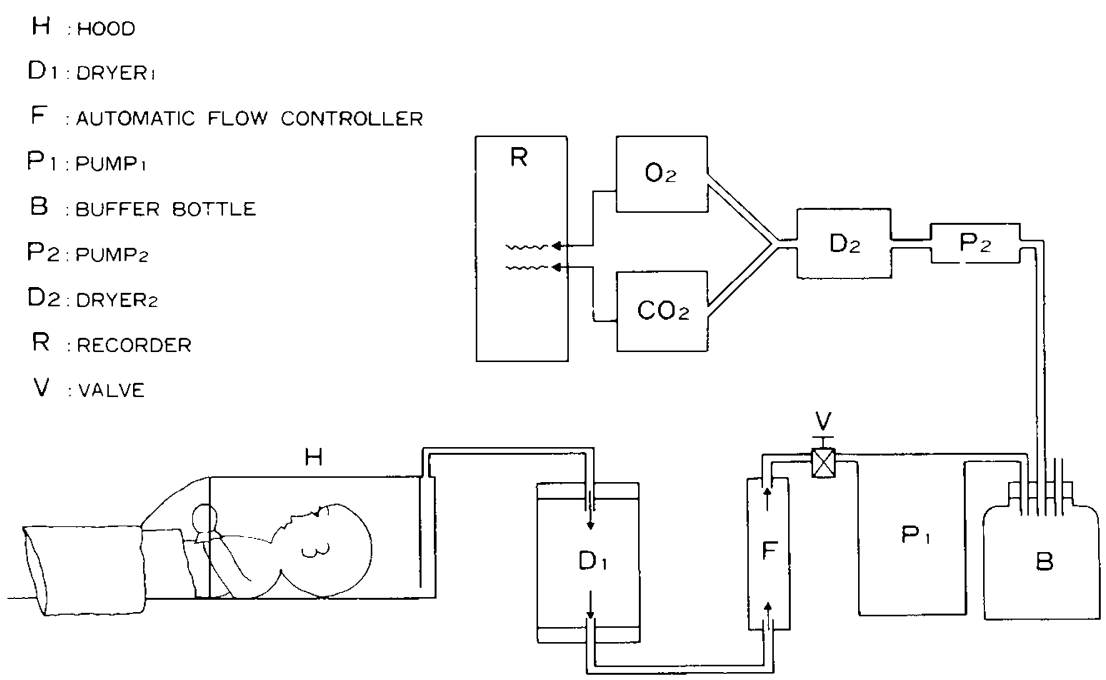

Fig. 1. Diagrammatic demonstration of open indirect calorimetry system used to measure oxygen consumption and carbon dioxide production.

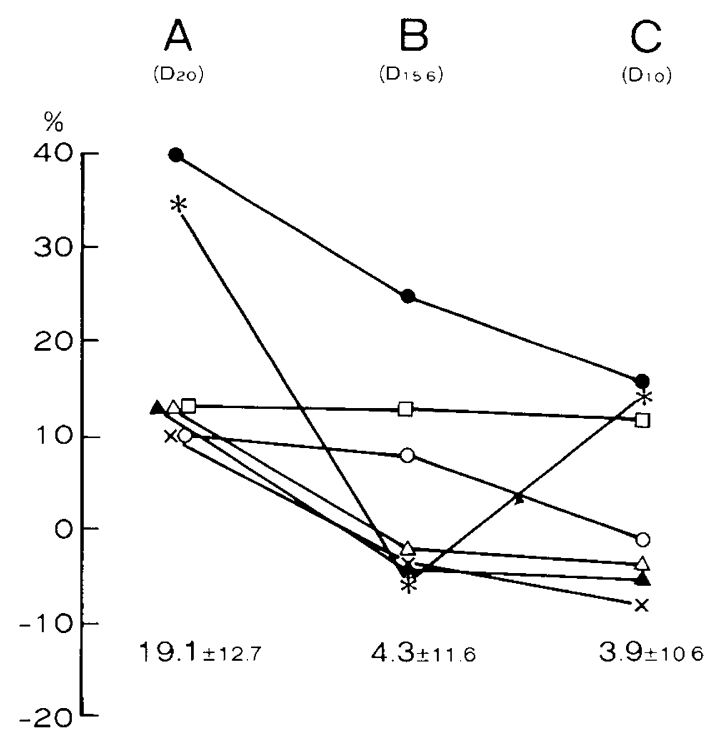

Fig. 2. BMR using formula $A$ compared to BMR using formula $B$ or $\mathrm{C}, \mathrm{A}$ versus $\mathrm{B}$ or $\mathrm{A}$ versus $\mathrm{C}, p<0.005$.

to avoid essential fatty acid deficiency, had BMR and RQ values which were significantly higher than those seen in intermediate or in fat-dominant formulations. Most investigators $(6,9)$ acknowledge that patients receiving a TPN solution, in which the energy source is predominantly or exclusively glucose, will experience a significant rise in the resting energy expenditure and will have RQ values greater than 1.0. This effect is seen in all but the most severely hypermetabolic patients (6). We show that infants and children have similar metabolic effects, with concomitant rises in BMR and RQ, when they are supplied with a glucose-dominant TPN regime.

Previous studies of energy metabolism $(4,6)$ were conducted in adult patients with severe catabolic states and are not comparable to results in the present study. Jeejeebhoy et al. (7) studied patients who had experienced a period of protein-calorie malnutrition prior to the study, many of whom had active infection and inflammatory processes. They found no significant difference in nitrogen retention between subjects receiving nonprotein calories as glucose alone and those receiving $83 \%$ of their calories from intravenous fat. In another study, Long et al. (8) found glucose-dominant formulations to be clearly superior to fat-dominant formulations with regard to nitrogen retention, but
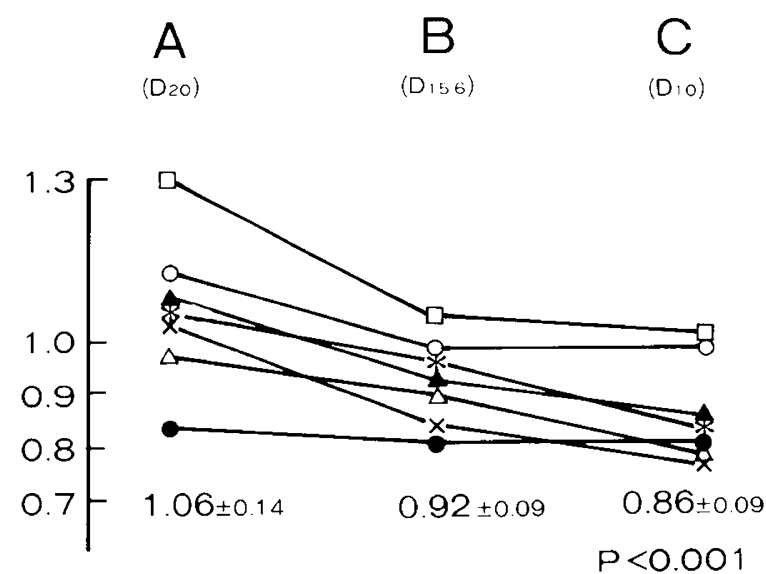

Fig. 3. RQ in each of seven patients measured on three different TPN formulas. RQ on TPN formulation A compared to B or C. A versus $\mathrm{B}$ or $\mathrm{A}$ versus $\mathrm{C}, p<0.001$.

Table 3. Percentage of carbohydrate, fat, and protein burned in energy expenditure and nitrogen retained

\begin{tabular}{|c|c|c|c|c|}
\hline & $\mathrm{A}\left(\mathrm{D}_{20} \mathrm{~W}\right)$ & $\mathrm{B}\left(\mathrm{D}_{15.6} \mathrm{~W}\right)$ & $\mathrm{C}\left(\mathrm{D}_{10} \mathrm{~W}\right)$ & $p$ \\
\hline Carbohydrate* & $81.8 \pm 20.5$ & $61.5 \pm 26.4$ & $45.5 \pm 29.7$ & $<0.05$ \\
\hline Fat* & $9 \pm 22$ & $31.9 \pm 25.3$ & $42.7 \pm 27.5$ & $<0.01$ \\
\hline Protein* & $9.3 \pm 2.6$ & $7.7 \pm 3.3$ & $10.3 \pm 3.6$ & NS \\
\hline $\begin{array}{l}\text { Nitrogen reten- } \\
\text { tion } \dagger\end{array}$ & $0.098 \pm 0.028$ & $0.163 \pm 0.060$ & $0.123 \pm 0.064$ & $<0.01$ \\
\hline
\end{tabular}

* Values recorded as mean \pm SD percentage burned.

$\dagger$ Values recorded as mean $\pm \mathrm{SD} \mathrm{g} / \mathrm{kg} /$ day.

the patients studied had abnormally high basal metabolic rates. There have been no previous studies of this kind in growing infants and children with normal metabolic needs and given clinically applicable TPN solutions.

While we have demonstrated that the pattern of fuel utilization in infants and children on TPN is strongly influenced by the energy sources, it must be kept in mind that the RQ in healthy (enterally fed) infants and children with normal growth and development, is approximately 0.85 . From this, the conclusion follows that RQ results in excess of 1.0 are not physiologic and, hence, the utilization of nearly $82 \%$ of the carbohydrate delivered in solution A (the high-carbohydrate, low-fat formulation; see 
Fig. 4), is similarly nonphysiologic as compared with solutions $\mathrm{B}$ or $\mathrm{C}$.

With regard to protein degradation as a component of fuel utilization, we observed no significant difference among the three solutions. This indicates, in part, that infants and children with normal metabolic requirements have a minimum level of nitrogen degradation and that this is independent of the composition of the energy source, at least within the limits of physiologic solutions. This result is consistent with the data of Rubecz et al. (10).

Our balanced solution (B) yielded the greatest nitrogen retention, as compared with the two other solutions (Table 3 ), in our eumetabolic children. The explanation for this is that although the percentage of nitrogen degradation is not strongly influenced by the energy source, the absolute amount of nitrogen retention with solution B was significantly greater than with solutions A and $C$, because the resting energy expenditure and BMR were higher with solution $A$ than values seen with administration of solution $\mathrm{B}$.

"Inefficient glucose utilization" is most likely to occur when large amounts of glucose are given. There is a physiologic maximum to glucose oxidation (11), which has been reported to range from $5(12)$ to $9 \mathrm{mg} / \mathrm{kg} / \mathrm{min}$, and varies depending on the patient's condition and concomitant metabolic needs (13). In the present study, the children on solution A oxidized approximately $15 \mathrm{mg} / \mathrm{kg} / \mathrm{min}$ of glucose, which, judging from the excessively high $\mathrm{BMR}$ and $\mathrm{RQ}>1.0$, exceeded the normal, physiologic maximum. In this regard, solutions $B$ and $C$, with their respective

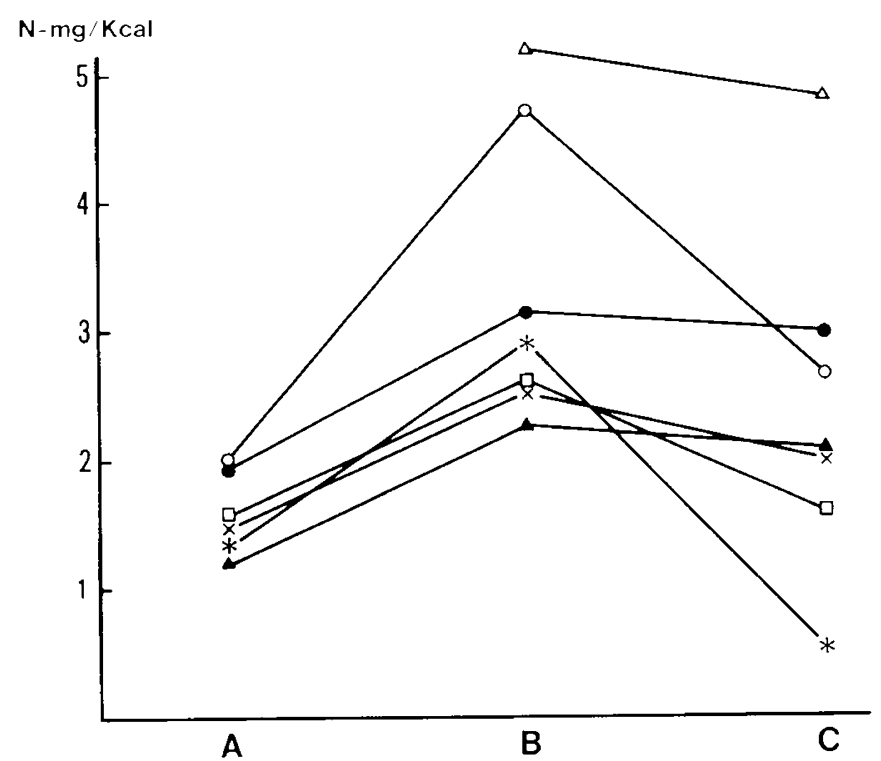

Fig. 4. Nitrogen retention/resting energy expenditure ratio. The mean ratio during administration of solution $\mathrm{B}$ was significantly greater than that during administration of solution $\mathrm{A}$ or $\mathrm{C}(p<0.001)$. average glucose oxidation rates of approximately 10 and $6 \mathrm{mg} /$ $\mathrm{kg} / \mathrm{min}$, were "more physiologic." While it is not yet possible to quantitate this physiologic maximum glucose utilization in infants and children, the results of the present study indicate that it is likely to be exceeded when glucose is the only nonprotein energy source given to patients receiving TPN. It follows that less energy, as ATP, would be available for anabolic processes such as protein synthesis, when glucose alone, as compared with a balanced, equicaloric glucose and fat regimen, is used. Moreover, such a formulation will require fewer calories for nitrogen retention than will a carbohydrate-dominant formulation, not only because it is associated with lesser increments in BMR, but because it ensures a more efficient utilization of the provided energy substrate.

Although we observed no difference in energy expenditure (expressed as BMR) between children given solutions $\mathrm{B}$ and $\mathrm{C}$, enhanced nitrogen conservation was noted with solution $\mathrm{B}$. Of the solutions studied, solution B, with its intermediate composition of $8 \%$ protein, $60 \%$ carbohydrate, and $32 \%$ fat, appears to be the most efficient formulation for TPN in growing infants and children with normal metabolic needs.

\section{REFERENCES}

1. O'Keefe SJ, Moldawer LL, Young VR, Blackburn GL 1981 The influence of intravenous nutrition on protein dynamics following surgery. Metabolism $30: 1150-1158$

2. Iapichino G, Solca M, Radrizzani D, Zucchetti M, Damia G 1981 Net protein utilization during total parenteral nutrition of injured, critically ill patients: an original approach. JPEN 4:317-321

3. Robin AP, Carpentier YA, Askanazi J, Nordenstrom J, Kenney JM 198 Metabolic consequences of hypercaloric glucose infusion. Acta Chir Belg 80:133-140

4. Stoner HB, Little RA, Frayn KN, Elebute AE, Tresadern J, Gross E 1983 The effect of sepsis on the oxidation of carbohydrate and fat. Br J Surg 70:32-34

5. Consolazio CF, Johnson RE, Pecora LJ 1963 Physiological Measurement of Metabolic Functions in Man. McGraw-Hill, New York

6. Askanazi J, Carpentier YA, Elwyn DH, Nordenstrom J, Jeevanandam M, Rosenbaum SH, Gump FE, Facs JM, Kinney JM 1980 Influence of total parenteral nutrition on fuel utilization in injury and sepsis. Ann Surg 191:40 46

7. Jeejeebhoy KN, Anderson GH, Nakhooda AF, Greenberg GR, Sandarson JI, Marliss EB 1976 Metabolic studies in total parenteral nutrition in man. J Clin Invest 57:125-136

8. Long JM, Colonel L, Wilmore DW, Mason AD Jr, Pruitt BA Jr 1977 Effect of carbohydrate and fat intake on nitrogen excretion during total intravenous feeding. Ann Surg 185:417-422

9. Macfie J, Holmfield JHM, King RFG, Hill GL 1983 Effect of the energy source on changes in energy expenditure and respiratory quotient during total parenteral nutrition. JPEN 7:1-5

10. Rubecz I, Mestyan J, Varga P, Klujber L 1981 Energy metabolism substrate utilization and nitrogen balance in parenterally fed postoperative neonates and infants. $\mathrm{J}$ Pediatr 98:42-46

11. Macfie J, Smith RC, Hill GL 1981 Glucose or fat as a nonprotein energy source? A controlled clinical trial in gastroenterological patients requiring intravenous nutrition. Gastroenterology 80:103-107

12. Burke JF, Wolfe RR, Mullany CJ, Mathews DE, Bier DM 1979 Glucose requirement following burn injury. Parameters of optimal glucose infusion and possible hepatic and respiratory abnormalities following excessive glucose intake. Ann Surg 190:274-285

13. Giovannini I, Boldrini G, Castagneto M, Sganga G, Nanni G, Pittiruti M Castiglioni G 1983 Respiratory quotient and patterns of substrate utilization in human sepsis and trauma. JPEN 7:226-230 